\title{
Predicting the distribution of a threatened albatross: The importance of competition, fisheries and annual variability
}

\author{
P. Catry ${ }^{\mathrm{a}, \mathrm{b}, *}$, R.T. Lemos ${ }^{\mathrm{c}, \mathrm{d}}$, P. Brickle ${ }^{\mathrm{e}, 1}$, R.A. Phillips ${ }^{\mathrm{f}}$, R. Matias ${ }^{\mathrm{a}, \mathrm{g}}$, J.P. Granadeiro ${ }^{\mathrm{h}}$ \\ ${ }^{a}$ Eco-Ethology Research Unit, ISPA, Rua Jardim do Tabaco 34, 1149-041 Lisboa, Portugal \\ ${ }^{\mathrm{b}}$ Museu Nacional de História Natural e da Ciência, Universidade de Lisboa, Portugal

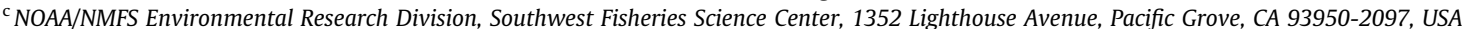 \\ ${ }^{\mathrm{d}}$ Centre for Applications in Natural Resource Mathematics (CARM), School of Mathematics and Physics, The University of Queensland, Brisbane St. Lucia, QLD 4072, Australia \\ e Falkland Islands Government, Directorate of Natural Resources, Fisheries Department, PO Box 598, Stanley FIQQ1ZZ, Falkland Islands \\ ${ }^{\mathrm{f}}$ British Antarctic Survey, Natural Environment Research Council, High Cross, Madingley Road, Cambridge CB3 OET, UK \\ ${ }^{\mathrm{g}}$ Centre for Ecology and Conservation, School of Biosciences, University of Exeter, Cornwall Campus, Penryn TR10 9EZ, UK

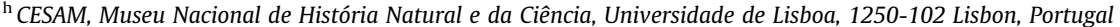

\section{A R T I C L E I N F O}

\section{Article history:}

Received 13 February 2012

Received in revised form 10 December 2012

Accepted 14 January 2013

Available online 1 February 2013

\begin{abstract}
A B S T R A C T
The ability to predict the distribution of threatened marine predators is essential to inform spatially explicit seascape management. We tracked 99 individual black-browed albatrosses Thalassarche melanophris from two Falkland Islands' colonies in 2 years. We modeled the observed distribution of foraging activity taking environmental variables, fisheries activity (derived from vessel monitoring system data), accessibility to feeding grounds and intra-specific competition into account. The resulting models had sufficient generality to make reasonable predictions for different years and colonies, which allows temporal and spatial variation to be incorporated into the decision making process by managers for regions and seasons where available information is incomplete. We also illustrated that long-ranging birds from colonies separated by as little as $75 \mathrm{~km}$ can show important spatial segregation at sea, invalidating direct or uncorrected extrapolation from one colony to neighboring ones. Fisheries had limited influence on albatross distribution, despite the well known scavenging behavior of these birds. The models developed here have potentially wide application to the identification of sensitive geographical areas where special management practices (such as fisheries closures) could be implemented, and would predict how these areas are likely to move with annual and seasonal changes in environmental conditions.
\end{abstract}

(c) 2013 Elsevier Ltd. All rights reserved.

\section{Introduction}

Past and predicted widespread changes in marine ecosystems demand intensive monitoring and improved management practices based on sound scientific data. Although many attributes of marine communities are poorly known, valuable insights may be derived from studies on species thought to convey information on particular components, such as, for example, spatial and temporal variations in the abundance of prey (Block et al., 2011). Seabirds are relatively easy to study and thus are increasingly being used for environmental assessment and monitoring (Boyd et al., 2006). Furthermore, many seabird species are globally threatened, hence their inclusion in frameworks for ecosystem-based management

\footnotetext{
* Corresponding author at: Eco-Ethology Research Unit, ISPA, Rua Jardim do Tabaco 34, 1149-041 Lisboa, Portugal. Tel.: +351 962445005.

E-mail addresses: paulo.catry@gmail.com (P. Catry),rtlemos@gmail.com (R.T Lemos), PBrickle@fisheries.gov.fk (P. Brickle), raphil@bas.ac.uk (R.A. Phillips), rfsmatias@gmail.com (R. Matias),jpgranadeiro@fc.ul.pt (J.P. Granadeiro).

1 Present address: South Atlantic Environmental Research Institute, PO Box 609, Stanley FIQQ 1ZZ, Falkland Islands.
}

of fisheries, in marine zoning and in the design of marine protected areas (Hyrenbach et al., 2000).

In this context, the ability to predict the distribution of threatened marine predators such as albatrosses, petrels and other seabirds is essential to inform spatially explicit seascape management (Louzao et al., 2011). The identification of hotspots where predators are concentrated has recently been placed high on the applied research agenda (White et al., 2002; Terauds et al., 2006; Falabella et al., 2009; Louzao et al., 2011). Understanding the factors responsible for, and making accurate predictions of seabird distributions is a progressing field but comprehensive models of the spatial distribution of marine predators are still scarce (Tremblay et al., 2009; Wakefield et al., 2009a).

During reproduction, seabirds are central-place foragers. Their at-sea distribution can be assessed through ship-based surveys or through remote tracking. Both methods have their own advantages, with tracking often better at distinguishing birds in transit from birds foraging, birds from different colonies of origin, or age and sex classes, and hence allowing the establishment of links between areas of high resource abundance where energy-transfer is taking place and population vital rates (reproductive output and 
survival). Furthermore, remote tracking allows the coverage of the entire marine area that is relevant for the animal populations under study, something that ship-based surveys rarely achieve.

Research suggests that birds from neighboring colonies can have markedly different at-sea distributions, which may result from intra-specific competition (Huin, 2002; Ainley et al., 2004; Grémillet et al., 2004; Trathan et al., 2006). Furthermore, inter-annual variation in oceanographic conditions may also be important (Kappes et al., 2010). Such sources of variability need to be incorporated in models attempting to predict the spatial distribution of seabirds. Scavenging seabirds, including black-browed albatrosses Thalassarche melanophris, often gather in huge flocks behind fishing vessels, taking advantage of escaped fish, discards and offal (Sullivan et al., 2006; Pierre et al., 2010). Hence, it is plausible that fishing fleets will also influence the distribution of tracked seabirds (Bartumeus et al., 2010), although some studies suggest that the attraction effect may be only of local nature (Skov and Durinck, 2001). Whatever the relationship, fishing vessel distribution needs to be taken into account. Most studies so far have examined this issue at coarse spatial and temporal scales (Xavier et al., 2004; Phillips et al., 2006; Weimerskirch et al., 2010, but see Peterson et al., 2008; Votier et al., 2010; Granadeiro et al., 2011 for important exceptions) and more work is needed in this area.

Here we developed models to predict the distribution of blackbrowed albatrosses foraging over the southern Patagonian shelf, part of the Patagonian large marine ecosystem and one of the most productive areas in the world (Arkhipkin et al., 2012). This area is made up of a temperate ecosystem in the north and a sub-Antarctic system in the south which is partitioned by a boundary running from south-west to north-east through the Falkland Islands (Boltovskoy, 1999). The region hosts outstanding populations of foraging marine mammals and seabirds, but so far no official marine protected areas for biodiversity conservation have been created here (Falabella et al., 2009). Black-browed albatrosses represent a large part of the avian biomass of this ecosystem. They are known to gather behind fishing vessels in large numbers, suffering heavy incidental mortality (Sullivan et al., 2006; ACAP, 2009), and are categorized as Endangered by the World Conservation Union (IUCN, 2008). Our study aimed to develop robust models for predicting the distribution of albatrosses, taking into account factors such as accessibility (or travel costs), intra-specific competition, oceanography, fisheries and the corresponding inter-annual variation. We tested our models using independent data sets obtained from different colonies and seasons, which represent one of the most stringent tests available to assess the generality and usefulness of predicted distributions and the relevance of explanatory covariates.

\section{Methods}

\subsection{Study sites and bird tracking}

Black-browed albatrosses were tracked during the brooding stage (December and early January) from colonies on New Island (in 2008/2009 and 2009/2010) and on Steeple Jason (2009/2010). New Island $\left(51^{\circ} 43^{\prime} \mathrm{S}, 61^{\circ} 18^{\prime} \mathrm{W}\right)$ holds ca. 12,000 black-browed albatross pairs, and Steeple Jason $\left(51^{\circ} 01^{\prime} \mathrm{S}, 61^{\circ} 13^{\prime} \mathrm{W}\right)$ holds ca. 200,000 pairs (the largest colony for this species). Tracking was conducted through the deployment of GPS loggers (E\&O Technologies, mass 25-30 g), attached to the mantle and scapular feathers, that recorded bird positions every 7 or every 14 min (depending on the size of the battery). Birds were also fitted with British Antarctic Survey geolocator-immersion loggers ( Mk 7; $3.5 \mathrm{~g}$ ) on a plastic or metal leg band, to record the timings of all changes of state (from wet to dry, and vice versa, with 3 s resolution). Estimated bird positions every $3 \mathrm{~s}$ were obtained through linear interpolation of GPS data and the location of all landings (on the sea) was inferred by combining the timings of locations with those provided by the logger data.

We tracked a total of 170 trips from 99 individual albatrosses (1-3 trips per individual) including 72 trips (39 birds) in 2008/ 2009, 65 trips ( 35 birds) in 2009/2010 on New Island and 33 trips (25 birds) from Steeple Jason.

\subsection{General approach and options}

We modeled the number of "dry-wet" transitions per $20 \times 20 \mathrm{~km}$ cell of the study domain, which was defined as the area $45-60^{\circ} \mathrm{S}, 55-70^{\circ} \mathrm{W}$. No foraging activity was recorded beyond this box. The immediate vicinity $(<1500 \mathrm{~m})$ of the study colonies, where birds often congregate to rest, was excluded as potential foraging area (see Granadeiro et al., 2011). The maximum foraging distance from the colony recorded during this study was $603 \mathrm{~km}$. We reasoned that marine areas where birds do not land are of comparatively minor relevance for albatrosses, as they do not provide resources, and hence of lower priority for special management. Taking-off from the sea surface is an energetically expensive exercise for albatrosses (Weimerskirch et al., 2000), and we therefore assume that landing is generally associated with foraging and is rarely conducted without purpose. Landing can also be associated with resting, but the proportion of landings with this function must be low in our study birds, which on average landed on the sea 60 times per day (Granadeiro et al., 2011). Furthermore, landing spots, even if not providing food sources, are relevant because birds can still be affected by oil spills or other sources of pollution.

We followed Wakefield et al. (2011) in suggesting that habitat suitability is determined by local biotic and abiotic features, its accessibility and from the competitive influence exerted by individuals from other colonies. Hence, we encapsulated these three types of factors in a habitat suitability index given by

$H_{i}(s)=Q(s) \frac{A_{i}(s)}{C_{i}(s)}$

In other words, starting from the habitat quality of a cell $s$ of the study grid $\left[H_{i}(s)\right]$, which is independent of the colonies where birds originate, we obtain the habitat suitability for colony $i$ by deflating the quality $[Q(s)]$, based on intra-specific competition $\left[C_{i}(s)\right]$ and the inverse of the cost of traveling between $i$ and $s$, which is given by the accessibility factor $\left[A_{i}(s)\right]$.

Dry-wet transitions typically present an aggregated spatial distribution, for a number of reasons: (i) they belong to the same bird; (ii) feeding of one bird may attract others; (iii) non-measurable environmental features such as the occurrence of food patches may also cause clustering (Grünbaum and Veit, 2003). For this reason we considered our dependent variable $\left(Z_{i}(s)\right.$ - the number of landings detected per cell) to have a negative binomial distribution, where the mean is proportional to $H_{i}(s)$. We estimated the overdispersion parameter, together with the parameters that define $H_{i}(s)$, using Poisson-gamma generalized linear models (GLMs) with log-link function (see Supplementary material 1). For this purpose we adapted the PRIMM software developed by Christiansen and Morris (1997) from the S language to $R$ - version 2.10.1 ( $R$ Development Core Team, 2009).

\subsection{Environmental quality factor}

We considered sea surface temperature (SST), chlorophyll- $a$ concentration (Chl) and depth and their gradients as potential determinants of environmental quality. Mean values per cell (plus 
quadratic terms) and gradients (Supplementary material 1) were tested as predictors of habitat quality.

Sea surface temperature and chlorophyll- $a$ concentration - Level 2 Modis Aqua and Terra data - were retrieved from http:// oceancolor.gsfc.nasa.gov/. The SeaBatch software (http://seabatch.com/) was used to detect and remove outliers, and to bin data into monthly $20 \times 20 \mathrm{~km}$ resolution products. SeaDAS (http://oceancolor.gsfc.nasa.gov/seadas/) was used to visualize data and to produce ASCII files for input to PRIMM. Etopo $1 \mathrm{~min}$ bathymetry data were retrieved from NOAA NGDC GEODAS (http://www.ngdc.noaa.gov/mgg/gdas/). Further data preprocessing, including the computation of gradients, was performed with purpose-built Fortran code. Ocean Data View (Schlitzer, 2010) was used for data visualization and preliminary analyses.

The models also incorporated the presence of fishing vessels, as revealed by the Vessel Monitoring System (VMS). Information on each of the fishing vessels operating inside Falkland Island waters was obtained through VMS that recorded the position of each vessel every $3 \mathrm{~h}$ (2008/2009) or every $1 \mathrm{~h}$ (2009/2010). This information constitutes a complete portrait of fishing activity in Falkland waters (as there are no vessels operating there without VMS), but not in Argentinean or international waters where data were unavailable. Nevertheless, we included the available fisheries data given that in different years and colonies between $53 \%$ and $87 \%$ of the black-browed albatross time at sea was spent in sectors with complete VMS data (Granadeiro et al., 2011). During the study period, the vessels operating in the area (15 vessels in the first year and 21 in the second) were freezer/factory bottom trawlers targeting finfish. The main target species was the Patagonian rock cod (Patagonotothen ramsayi). Fishery products include headed and gutted trunks, fillets and skate wings, with offal, heads and under-sized fish or unwanted species being discarded directly and not minced (see Granadeiro et al., 2011 for more details). Fishing effort of the Falklands fleet was estimated based on hourly positions of vessels moving at $<6$ knots (in 2008, values were interpolated to $1 \mathrm{~h}$ ). This speed filter was supported by a bimodal distribution of vessel speeds, and probably excludes the majority of vessels in rapid transit between hauling stations.

\subsection{Accessibility factor}

Albatrosses are central-place foragers that fly using dynamic soaring. Hence, habitat accessibility is a function of distance from the colony (Matthiopoulos, 2003; Aarts et al., 2008), together with wind velocity and direction, which affect air speed and energy cost per unit time (Weimerskirch et al., 2000; Wakefield et al., 2009b). We assumed that accessibility may not vary linearly with distance (it may increase faster, per unit distance, at greater distances from the colony) because of the need to provide food for offspring at regular intervals. As expounded in Supplementary material 1, we constructed the accessibility factor $\mathrm{Ai}(\mathrm{s})$ by taking all these factors into account. From daily ASCAT and QuikSCAT passes (ftp://podaac.jpl.nasa.gov/), we separately computed averages of zonal (East-West) and meridional (North-South) wind components; with these, we obtained the monthly mean vector of sea-level wind.

\subsection{Competition factor}

Within our study domain, there are 12 islands with black-browed albatross colonies in the Falklands, two large populations in Chile at the Diego Ramirez and Ildefonso island groups, and 2 small colonies on islands in southern Tierra del Fuego (ACAP, 2009). These include several large colonies holding in excess of 10,000 breeding pairs.
In our model, we take possible intra-competition effects into account by considering that habitat suitability for birds of a given colony is affected by the habitat's proximity to other colonies, in particular those of large size (see Supplementary material 1). Estimates of colony sizes were obtained from Huin and Reid (2007), Strange (2008) and ACAP (2009).

\subsection{Validation}

We carried out several tests to confirm the validity and generality of the main findings obtained from the models.

\subsubsection{Validation of parameter estimates}

We fitted three GLMs: the first used data from New Island in 2008/2009; the second used 2009/2010 data from the same colony; the third used data from Steeple Jason in 2009/2010. For each GLM, predictors were selected with a backward stepwise approach. If our conceptualization of habitat suitability and use is not too far from the truth, and if the fitting algorithm does not lead to spurious results, then the $z$-scores for any given parameter should vary little over the three GLMs. Conversely, if we have failed to capture nonlinearities, missed important factors, fitted the model incorrectly or overfitted the data provided, then the three GLMs should provide widely different parameter estimates.

\subsubsection{Validation of spatial predictions}

We produced maps of the distribution of observed and expected dry-wet transitions, separately for New Island in 2008/2009 and 2009/2010, and Steeple Jason in 2009/2010. By "expected values" we refer to the posterior mean of $Z_{i}(s)$, according to the model fitted with data from New Island in 2008/2009 only. With this procedure, we tried to detect strengths and weaknesses in the model, i.e., areas where observations and expected values showed the greatest or least correspondence.

\subsubsection{Validation of factors}

We investigated the contribution of the factors considered to affect the habitat suitability index by using the Akaike Information Criterion with a correction for finite sample sizes (AICc). Starting from a complete model, we removed predictors (one at a time) and examined the resulting AICc. To compare the resulting models to the full and to the null models, we computed

$\Delta_{j}=\frac{\operatorname{AICc}(j)-\operatorname{AICc}(\text { complete })}{\operatorname{AICc}(\text { null })-\operatorname{AICc}(\text { complete })}$

which may be interpreted as the loss of the explanatory power of a submodel, relative to the complete model (Burnham and Anderson, 2002). Values close to 0 indicate minimal loss, while values close to 1 indicate total loss.

\subsubsection{Validation of predictor-response curves}

For each predictor variable, we compared binned means (or frequencies) of dry-wet transitions with corresponding 95\% credibility intervals provided by the model. Exactness, precision and sensitivity criteria were considered to determine if the GLM link function was appropriate and the correct functional form was chosen. See Supplementary material 2 for details.

\subsection{Inter-annual variability}

During preliminary analysis of New Island data, we observed marked differences in the spatial distribution of 2008/2009 and 2009/2010 landings. To evaluate which distribution is more typical, we constructed a map of the expected mean occurrence of dry-wet transitions made by New Island birds, during the month 
of December, using climatological (i.e., decadal mean) SST, chlorophyll, and wind conditions. The New Island 2009/2010 GLM was used in this exercise. QuikSCAT wind climatology (1999-2008) was provided by Risien and Chelton (2008, data available at http://cioss.coas.oregonstate.edu/scow/). Upon preliminary inspection of these products, we observe that blooms (i.e., concentrations above $10 \mathrm{mg} / \mathrm{m}^{3}$ ) are not present in the climatological chlorophyll product; more importantly, climatological wind vectors are spatially smoother and have smaller magnitude than those of December 2008 and 2009. Long-term means smooth out extremes, as expected, but we suspect that in the case of winds the difference in magnitudes may originate from the additional harmonic filtering performed by Risien and Chelton (2008) and/or the data source itself (ASCAT vs. QuikSCAT; Bentamy et al.,
2012). To mitigate this problem, we decrease the intercept for the climatological prediction model by 2.5 units. Such subjective procedure nearly eliminates the bias in the global mean impact of wind on expected dry-wet transitions, while keeping the spatial ratios intact. In other words, the correction has no impact on the determination of the regions more frequented by the birds.

\section{Results}

During early chick-rearing, black-browed albatrosses from the west Falklands foraged over the Patagonian Shelf, mostly to the west and southwest of the nesting colonies (Fig. 1). The distributions of landing events of albatrosses in 2009/2010 showed clear differences in relation to the colony of origin, in a pattern consis-
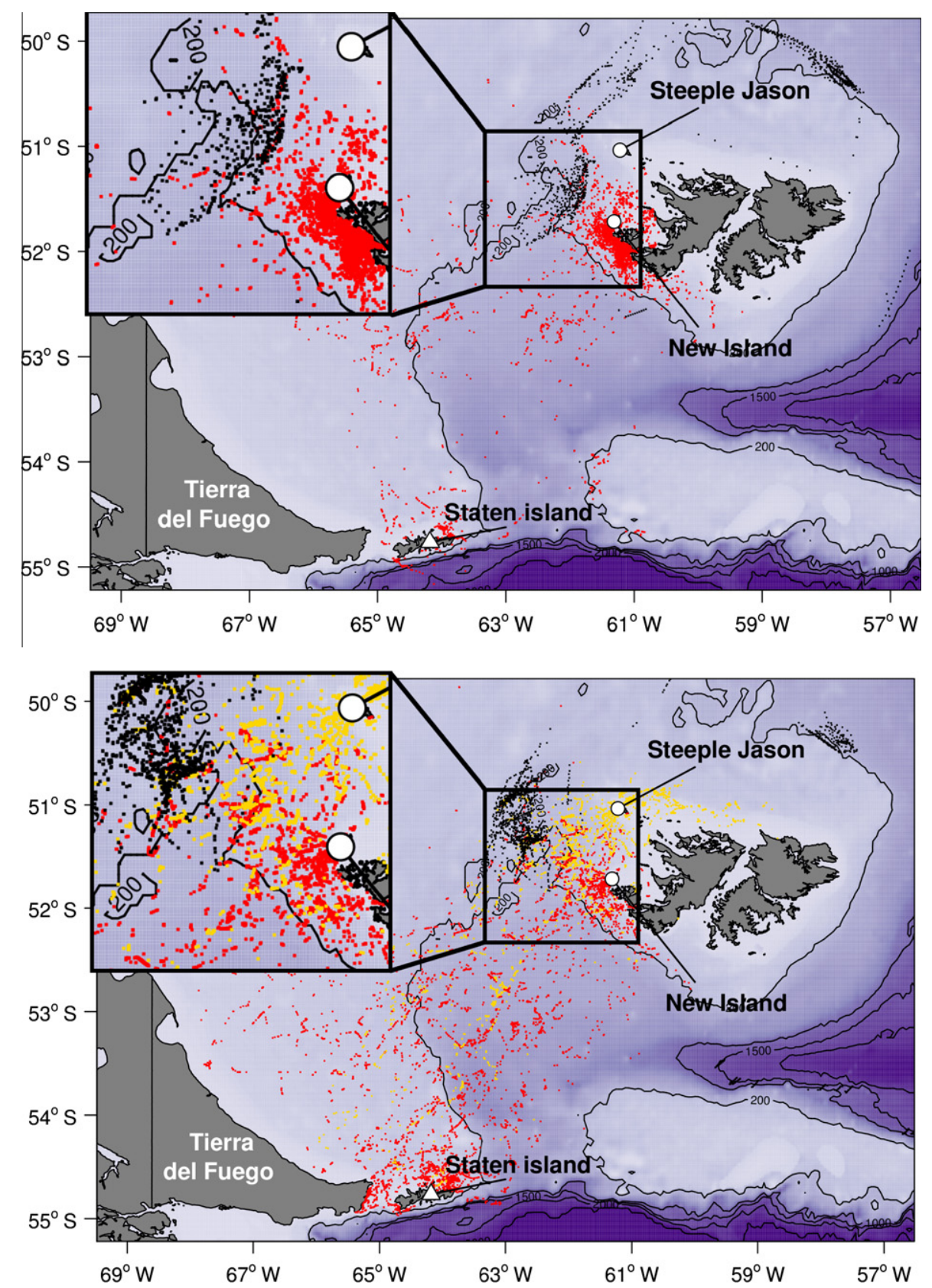

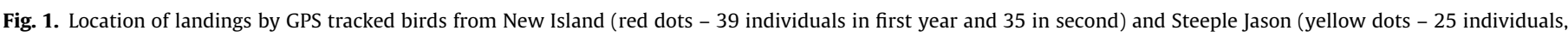

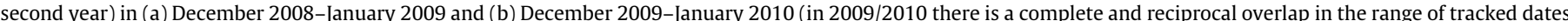

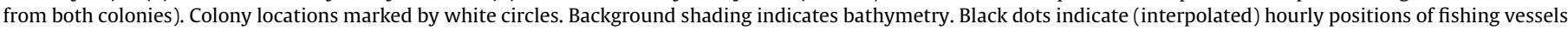
obtained from VMS of the Falkland Island licensed fishing fleet, steaming at or below 6 knots. 
Table 1

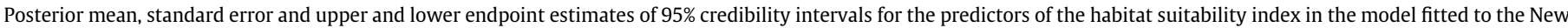

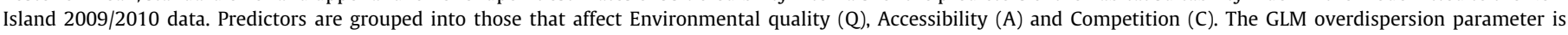
denoted as delta.

\begin{tabular}{|c|c|c|c|c|c|}
\hline & Estimate & SE & $\mathrm{EST} / \mathrm{SE}$ & Low point estimate & High point estimate \\
\hline Intercept & -2.354 & 1.459 & -1.614 & -5.213 & 0.505 \\
\hline \multicolumn{6}{|l|}{$Q$} \\
\hline Log(bathymetry) (bat) & -1.586 & 0.167 & -9.512 & -1.913 & -1.259 \\
\hline $\log (\text { bathymetry })^{2}$ (bat2) & 5.358 & 1.110 & 4.828 & 3.183 & 7.534 \\
\hline Gradient of Log(bathymetry) (batG) & 0.522 & 0.128 & 4.088 & 0.272 & 0.772 \\
\hline Log(chlorophyll- $a$ concentration) (chl) & 0.472 & 0.077 & 6.128 & 0.321 & 0.623 \\
\hline $\log (\text { chlorophyll- } a \text { concentration })^{2}(\mathrm{chl} 2)$ & 1.347 & 0.226 & 5.964 & 0.904 & 1.789 \\
\hline Log(sea surface temperature) (sst) & 0.138 & 0.811 & 0.170 & -1.451 & 1.727 \\
\hline Gradient of $\log$ (sea surface temperature)(sstG) & 11.780 & 3.657 & 3.221 & 4.612 & 18.950 \\
\hline Log(density of fishing vessels) (vms) & 0.015 & 0.007 & 2.176 & 0.002 & 0.029 \\
\hline \multicolumn{6}{|l|}{$A$} \\
\hline Log(overhead cost of flight) (ocost) & -5.810 & 0.823 & -7.062 & -7.422 & -4.197 \\
\hline Log(distance to the colony) (dist) & -1.941 & 0.187 & -10.390 & -2.307 & -1.575 \\
\hline \multicolumn{6}{|l|}{ C } \\
\hline Log(scaled distance to closest colony) (dmin) & -1.564 & 0.179 & -8.760 & -1.914 & -1.214 \\
\hline Log(size of closest colony) (dsize) & -0.115 & 0.011 & -10.890 & -0.136 & -0.094 \\
\hline Overdispersion parameter (delta) & 0.150 & 0.010 & 15.050 & 0.132 & 0.171 \\
\hline $\log ($ overdispersion parameter) $(\log ($ delta $))$ & -1.896 & 0.066 & -28.530 & -2.026 & -1.766 \\
\hline
\end{tabular}
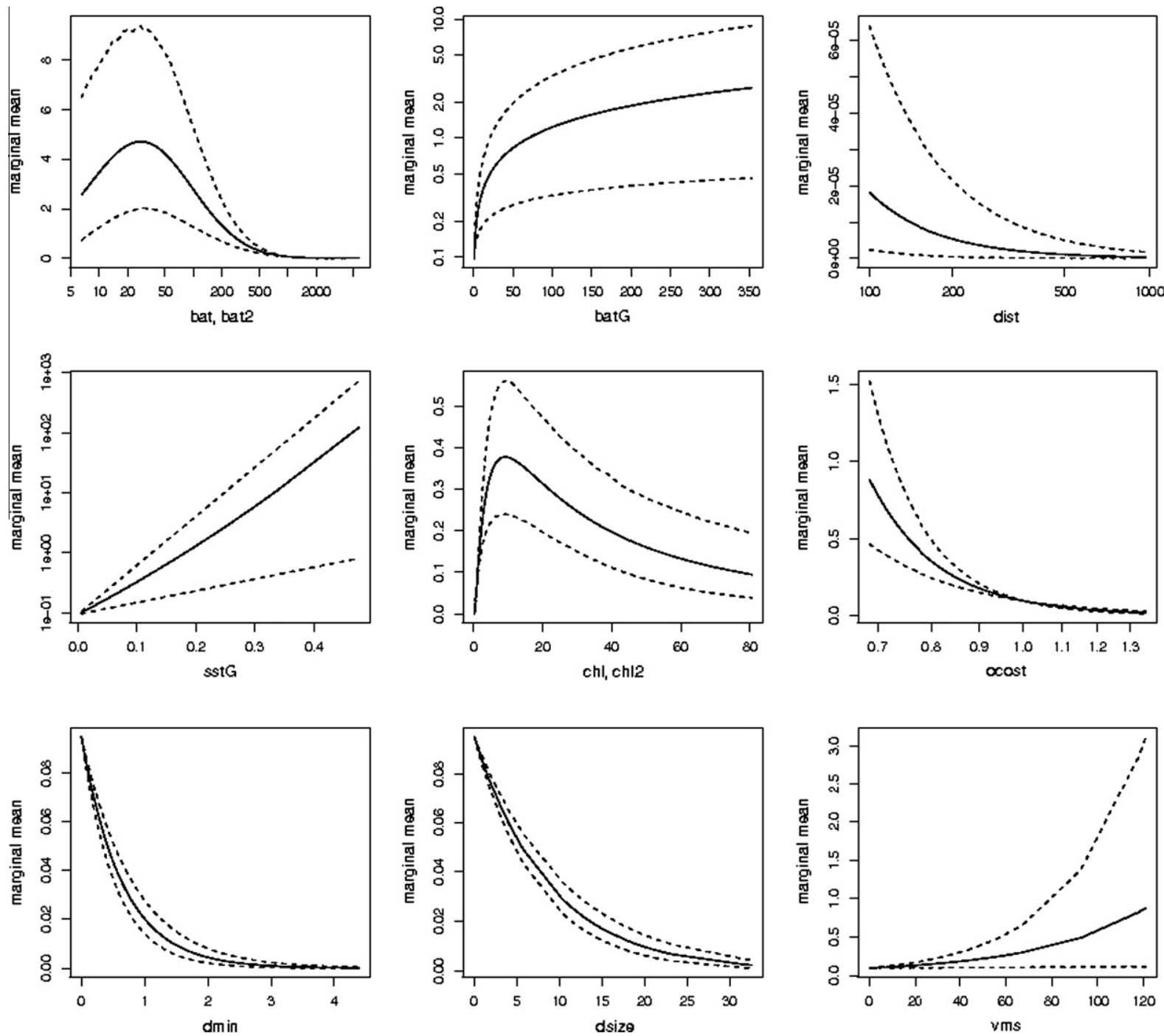

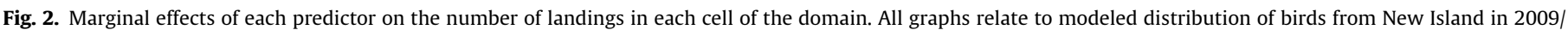
2010. Dashed lines indicate estimated 95\% CIs. 
tent with reciprocal avoidance of birds from adjacent sites (Fig. 1b). There were also clear inter-annual differences in the distribution of albatrosses from New Island: in the first year landings were tightly clustered near the colony, to the southwest and the south, while in the second year landings were more dispersed, and there was a much greater use of the distant area around Staten Island (east of Tierra del Fuego). There was a limited overlap between foraging activity and human fisheries (Fig. 1).

The coefficients of the habitat suitability model for New Island birds in 2009/2010 are presented in Table 1. Overall, this model and the ones fitted to New Island 2008/2009 and Steeple Jason data agreed in both sign and absolute value of coefficient $z$-scores (Fig. 1 of Supplementary material 2). Bathymetry, chlorophyll- $a$ and distance from the colony displayed consistently strong associations with landings, while SST was more important to explain Steeple Jason landings than New Island's. Conversely, colony-related quantities were better predictors for New Island landings. Given that three GLMs fitted to distinct data sets produced similar results, we believe that the associations between landings and covariates are not spurious.

Ceteris paribus, the expected number of landings is higher in waters with $20-50 \mathrm{~m}$ depth, and close to zero outside the continental shelf (Fig. 2, top left panel). Oligotrophic regions with strong gradients in SST and bathymetry seem preferred. Distance between habitat and colony, together with additional costs of flight due to wind conditions, also affect expected habitat use (Fig. 2). While the impact of fishing vessels includes substantial uncertainty (Fig. 2, bottom right panel), the proximity of other colonies, particularly the larger ones, is clearly detrimental for habitat use.

We used the model derived for New Island in 2008/2009 to predict the distribution of landings by colony and year, and compared those with the observed distribution (Fig. 3). On average, the model derived for New Island in 2009/2010 differed from the observations by 3.8 landings per grid cell. This mean absolute difference (MAD) rises to 25.1, if zero-count cells are excluded. When used to predict the distribution of landings for a different colony or a different year (i.e., the coefficients are fixed and new predictor values are provided), this model did not lose precision: $\mathrm{MAD}=3.3$ for New Island 2008/2009 data, and MAD = 2.8 for Steeple Jason 2009/2010 data. If zero-count cells are excluded, the values become 25.2 and 18.2 , respectively. These results are encouraging, since the number of landings per cell ranges from 0 to 1435 . Fig. 3 presents a visual comparison of observed and predicted values. The most marked changes in the relative distribution for New Island birds from 1 year to another, including the greater concentration of landings around the nesting colony, and a reduction of activity near Staten Island and Tierra del Fuego in 2008/2009, are well captured by the model. The distribution of birds from Steeple Jason is also predicted reasonably well, although for all models there is a considerable area to the NE where predictions are not confirmed by observations. Note that the three distributions are quite different, which shows that the model has enough flexibility and responsiveness under different ranges of biotic and physical conditions.

All three components included in the habitat suitability index were important for the models' predictive capability, and for interpreting the distribution patterns of New Island birds. Of these, environmental quality was the most important, followed by competition and accessibility (Table 2). The similarity in results for New Island in 2008/2009 and 2009/2010 is striking. We interpret this as evidence that the predictors included in the model are key determinants of habitat use. The competition factor was relatively unimportant for Steeple Jason (Table 2), possibly because this is the largest colony in the Falkland Islands and therefore the impact of neighboring colonies is likely to be low, in comparison with the situation for birds from New Island. Another noteworthy aspect of the models was the minimal and marginally
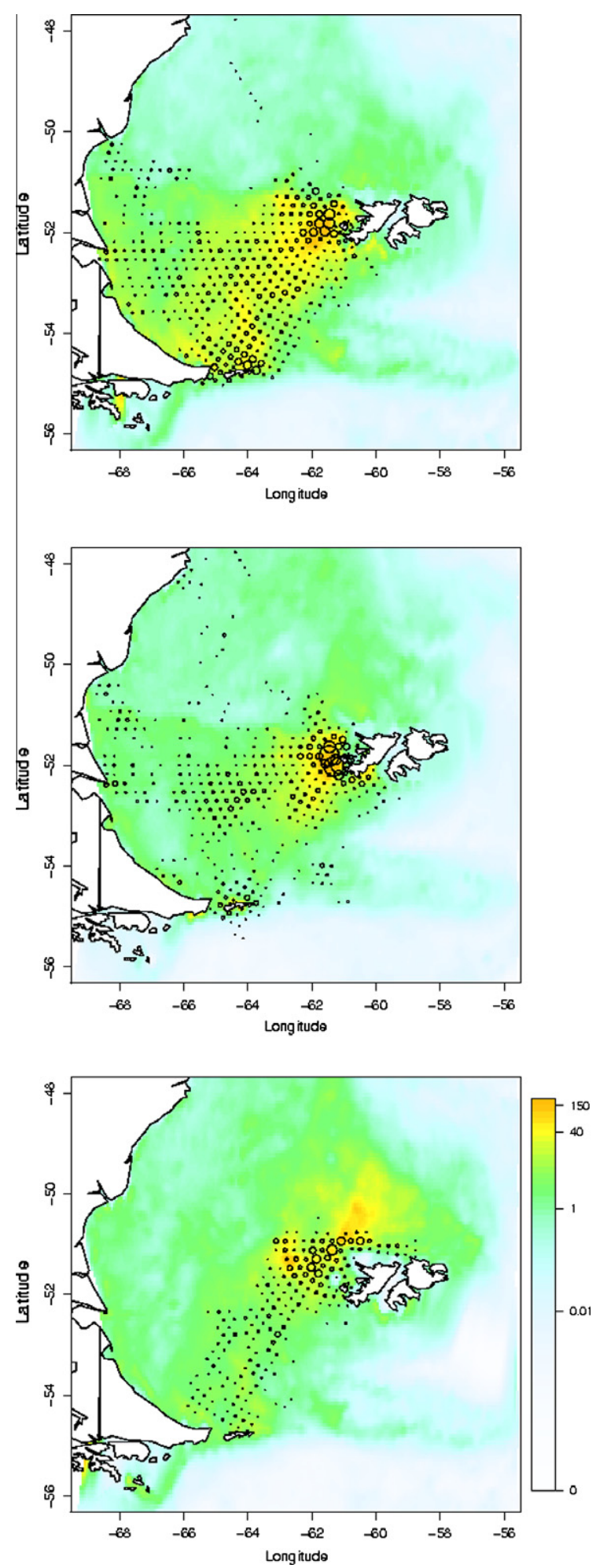

Fig. 3. Predicted number of landings (color log-scale) and observed values (black circles - circle area proportional to total number) for: (a) New Island 2009/2010; (b) New Island 2008/2009; (c) Steeple Jason 2009/2010. Predictions utilize a model whose coefficients were estimated from New Island 2009/2010 data only.

significant contribution of the fisheries predictor, which was responsible for no more than $2.3 \%$ of total explanatory power (Table 2). Fig. 4 provides visual support and further reinforces the conclusion extracted from Table 2 that each of the three main factors (environmental quality, accessibility and competition) are impor- 
Table 2

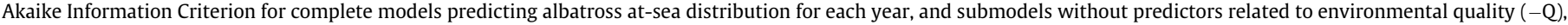

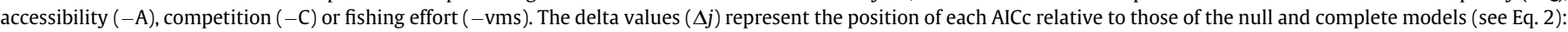

\begin{tabular}{|c|c|c|c|c|c|c|}
\hline & \multicolumn{2}{|c|}{ New Island 2008/2009 } & \multicolumn{2}{|c|}{ New Island 2009/2010 } & \multicolumn{2}{|c|}{ Steeple Jason 2009/2010 } \\
\hline & AICc & $\Delta j$ & AICc & $\Delta j$ & AICc & $\Delta j$ \\
\hline Complete & 124195.3 & 0.000 & 137067.2 & 0.000 & 54701.3 & 0.000 \\
\hline$-Q$ & 124592.0 & 0.373 & 137629.8 & 0.494 & 54986.0 & 0.324 \\
\hline$-\mathrm{A}$ & 124383.1 & 0.177 & 137264.9 & 0.174 & 55214.5 & 0.583 \\
\hline$-\mathrm{C}$ & 124402.2 & 0.195 & 137279.1 & 0.186 & 54713.2 & 0.013 \\
\hline$-\mathrm{vms}$ & 124196.7 & 0.001 & 137075.4 & 0.007 & 54721.1 & 0.023 \\
\hline Null & 125258.6 & 1.000 & 138205.4 & 1.000 & 55581.1 & 1.000 \\
\hline
\end{tabular}
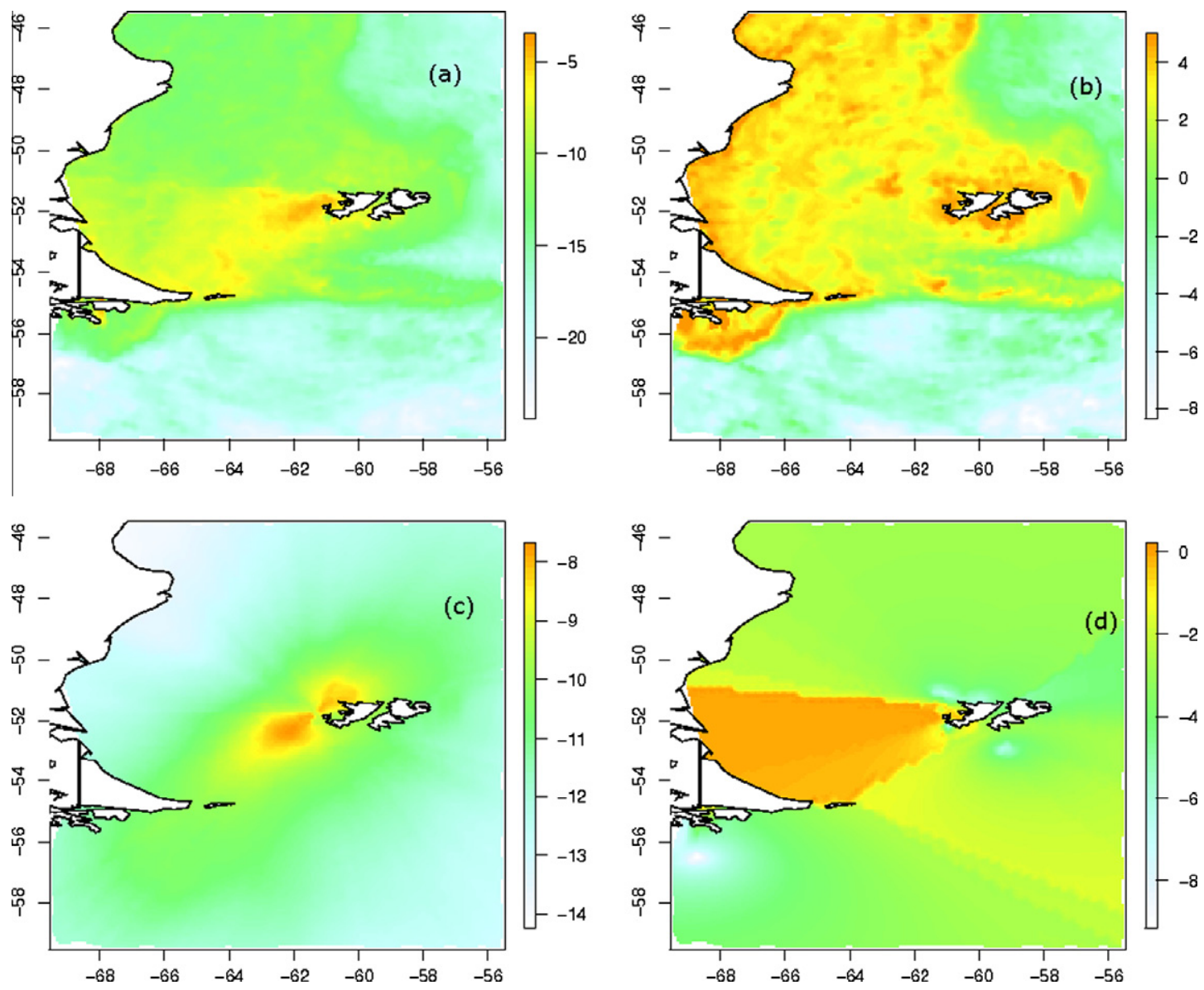

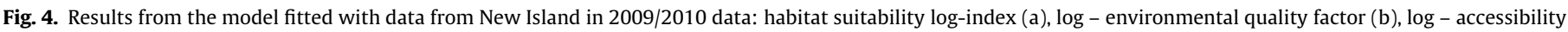
factor (c), log - competition factor (d).

tant in defining the habitat suitability index, and hence in predicting the distribution of New Island birds (as depicted in Figs. 1 and 3).

With the exception of the zonal wind component, the 20002009 environmental climatology is more similar to the environmental conditions in 2008 than in 2009 (Table 3). It is therefore not surprising that, when this climatology is provided to a previ-

Table 3

Mean of the absolute differences (MAD) between environmental conditions in December 2008 and 2009 and the 2000-2009 December climatology, for the study region.

\begin{tabular}{lllll}
\hline & SST & Chl- $a$ & u-wind & v-wind \\
\hline 2008 - Climatology & 0.39 & 1.38 & 4.56 & 1.60 \\
2009 - Climatology & 0.47 & 3.54 & 2.45 & 3.48 \\
\hline
\end{tabular}

ously fitted GLM, the resulting posterior predictive mean field of landings (Fig. 5) resembles that of 2008/2009 (MAD = 3.1 landings per cell) more than that of 2009/2010 (MAD $=4.0$; see also Fig. 3 ): habitat use near Staten Island is reduced, and most landings occur within $500 \mathrm{~km}$ west of the Falkland Islands.

\section{Discussion}

The present investigation incorporated several unusual or even unique features in the analysis of the distribution and habitat selection of pelagic predators under the central-place constraint. First, we used a large number of individuals providing few data each, rather than the more usual pattern of many data from fewer predators. Second, we focused our analyses on places where birds landed (calculated with fine-scale high quality data with minimal error) rather than using the entire route or trying to infer search 


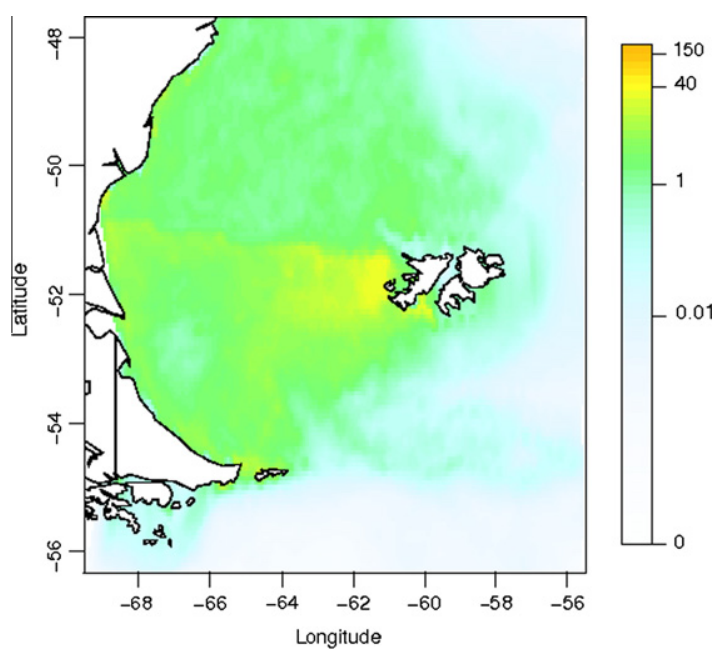

Fig. 5. Expected mean occurrence of landings of birds from New Island in December, when climatological (2000-2010) data are provided as input to the $2009 / 2010$ model of the habitat suitability index.

and feeding areas from first-passage time analyses or other techniques likely to involve more uncertainty. Third, we used a modeling technique that is suitable for overdispersed data, i.e. data whose variability exceeds that predicted by a Poisson model. Fourth, we took accessibility and intra-specific competition into account. Fifth, we had high quality data on movements of fishing vessels in the area most used by the study birds. Sixth, by using data from more than 1 year and more than one colony, we were able to stringently test our models. Finally, we were able to assess how inter-annual variation is likely to influence any conclusions concerning the most important areas for the birds of the study colonies during early chick rearing.

\subsection{Model strengths and weaknesses}

We subjected the Poisson-gamma GLM to a suite of tests, in order to validate results. In all cases, we concluded the model fitted the data correctly and provided valuable insight into novel configurations of the predictors. The use of a Poisson-gamma GLM is a suitable alternative to the Generalized Additive Models (GAMs), also successfully used in these contexts (Aarts et al., 2008; Wakefield et al., 2011). GAMs are more flexible, but they lack a parametric formulation and so they are less useful for application with other datasets. Also, the larger flexibility of GAM can create response-predictor relationships which are potentially difficult to interpret, and are more susceptible to the influence of outliers. The GLM overdispersion parameter, highly relevant in all our models (Fig. 1 of Supplementary material 2, Table 1), enables a flexible relationship between mean and variance (Supplementary material 1). For our specific application, the overdispersion parameter allows the model to cope with residual spatial aggregation patterns, due to factors for which no information could be gathered, such as short-term meso-scale features and mutual attraction by feeding conspecifics. Together with other validation tests, the relative success of the New Island GLM (in 2009/2010) in predicting the distribution of albatrosses in another year and at another colony, as well as the results from the other tests, strongly support the validity and robustness of the modeling approach.

There were some mismatches between predictions and observations, particularly in an area immediately to the north of the Falkland Islands. A certain level of discrepancy is expected, as the available environmental information (depth, SST, chlorophyll) are no more than proxies for the actual cues used by black-browed albatross when foraging; the competition and accessibility components also required simplifications for reasons of parsimony and tractability. Still, we believe that this shortcoming does not compromise the usefulness of the models. It is important to note that the predicted area of usage north of the Falklands is indeed intensively used, at least in some years, by black-browed albatrosses from another colony (Huin, 2002).

We studied the foraging distribution of albatrosses at a particularly sensitive phase of their nesting cycle, the brooding stage. Most Thalassarche albatross chick mortality occurs at the end of this stage, and adult birds lose considerable body reserves during this period (Catry et al., 2006). Under presumably severe energetic and time constraints (the need to regularly attend and feed the offspring) accessibility of foraging areas is expected to have a major bearing on their relative use, and hence the general evaluation of habitat suitability (Matthiopoulos, 2003). Models that did not take accessibility into account lost considerable explanatory power, which suggests that both distance to colony and wind patterns are relevant in foraging decisions made by albatrosses and need be taken into consideration when trying to predict their behavior and distribution (see also Wakefield et al., 2009b).

\subsection{Competition}

The Cairns (1989) hinterland model proposes that foraging zones of adjacent seabird colonies should show virtually no overlap. This model has received considerable support from some studies (Wanless and Harris, 1993; Grémillet et al., 2004; Masello et al., 2010), but several others documented a broad range of overlaps in foraging areas (Ainley et al., 2004; Wakefield et al., 2011). The very fine-scale data presented here clearly indicate a mixed picture, with a large area of overlap in terms of maximum extent, but obvious avoidance by birds from New Island of the main foraging area used by albatrosses from Steeple Jason, and vice versa. This last observation justifies the inclusion of a competition factor when modeling habitat suitability (see also Wakefield et al., 2011). In fact, the removal of the competition factor from the models for New Island resulted in a major loss of predictive power (see Table 2). The importance of this factor is likely to be even greater when considering inshore waters around the Falkland Islands. Note for example that New Island birds only use a narrow sector of coastal waters, despite their apparently high environmental quality (Fig. 4b). Such areas are in fact used by foraging birds from neighboring colonies (Fig. 1 and Huin, 2002), and given that they are well within the foraging ranges of New Island albatrosses, it seems highly likely that they are not used simply as a result of intra-specific competition.

Theoretical models and empirical observations suggest that colonial birds from large colonies should, on average, travel further to find adequate feeding grounds (Furness and Birkhead, 1984; Lewis et al., 2001). However, there are several data sets apparently disproving this hypothesis (Ainley et al., 2004; Wakefield et al., 2011). Moreover, even though ca. 15 times as many black-browed albatrosses breed at Steeple Jason than at New Island, there was no indication that the former had a larger foraging domain (Fig. 1, see also Granadeiro et al., 2011), and hence there seems to be no strong reason to include the size of the colony of origin as a single predictor variable in habitat suitability models.

\subsection{Habitat preferences}

Black-browed albatrosses have long been known to show a strong, but not obligatory, association with shelf and shelf-break waters, although the underlying preference is likely to be modulated by other factors (Weimerskirch et al., 1988; Waugh et al., 1999; Huin, 2002; Wakefield et al., 2011). The present study pro- 
vides an unusually fine picture of such a relationship and suggests, in the study domain, a selection of very shallow waters (around ca. $50 \mathrm{~m}$, see Fig. 2) as well as an association with areas of steeper seafloor slope (Fig. 2). The distribution pattern of the study birds around Staten Island is interesting from this perspective. Despite the close proximity of different bathymetric habitats, tracked birds clearly concentrated in neritic waters and made little use of the immediately adjacent steep shelf break (Fig. 1). This is despite the disproportionate use of areas with a greater bathymetry gradient (see also Wakefield et al., 2011), and indicates that black-browed albatrosses prefer areas with steep seafloor even when foraging exclusively over the continental shelf. This may happen because in these areas there is a greater hydrodynamic activity, with enhanced productivity and prey concentration (Acha et al., 2004).

The zones intensively used by albatrosses immediately $\mathrm{W}$ and SW of West Falkland represent a productive shallow area, where there is enhanced mesoscale activity and eddies are often formed by the northward flow of the west Falkland current (Arkhipkin et al., 2010). This region is also a spring spawning area for pelagic fish including the Fuegian sprat Sprattus fuegensis and the southern blue whiting Micromesistius australis (Agnew, 2002), which are common prey for black-browed albatrosses (own unpubl. data), and also for demersal fish such as red cod Salilota australis (Arkhipkin et al., 2010). It is also an important feeding area for South American fur seals Arctocephalus australis (Thompson et al., 2003) and several seabirds, particularly penguins (Falabella et al., 2009; Masello et al., 2010).

Another area of obvious concentration of foraging effort includes the waters surrounding Staten Island, at the eastern tip of Tierra del Fuego (Fig. 1). In this area there is a highly energetic hydrographic front and important spawning grounds for the Fuegan spratt (Acha et al., 2004). The area around Staten Island, and immediately north of it, is also much used by southern giant petrels Macronectes giganteus and black-browed albatrosses from Chile (Falabella et al., 2009). Staten Island harbors very large colonies of penguins (which forage in its vicinity) and its waters are exploited by commercial fisheries (Schiavini et al., 1999), which also underscore the biological importance of the zone.

\subsection{Fisheries}

Several studies have documented significant overlap, at various scales, between fishing fleets and the foraging ranges of marine predators (Hyrenbach and Dotson, 2003; Phillips et al., 2006), but without suggesting a causal relationship. If the presence of fishing fleets influences the at-sea distribution of predators (particularly those that regularly scavenge behind vessels), efforts to identify areas of special conservation significance might be to a certain extent compromised. If the purpose of documenting areas where predators concentrate is to better regulate fishing activities through management decisions such as temporary closures or changes in discard management (e.g. Pierre et al., 2010), then there is a risk that the distribution of the species to be safeguarded might change as consequence of those very management practices, requiring further reassessment of the entire process.

A fine scale analysis of black-browed albatross and fishing vessel interactions using the present data set suggested that New Island and Steeple Jason birds showed limited reliance on fisheries during early chick rearing (Granadeiro et al., 2011). The present study further illustrates (Fig. 1) there is little geographical overlap between albatrosses and the fishing fleet and, more importantly, suggests that the presence of fishing vessels makes only a marginal contribution to the suitability of habitats used by foraging albatrosses at this time of year (Table 2). These studies and other research (Skov and Durinck, 2001; Peterson et al., 2008) indicate that although seabirds often aggregate in large numbers behind fishing vessels, this should not be automatically taken as implying that their broad at-sea distribution responds to the spatial pattern of fisheries in general.

\subsection{Seascape management}

Despite the remarkable predictive power of the models, in some areas there was a poor correspondence between expected and observed distributions (Fig. 3). It is beyond the scope of this paper to discuss in detail the many reasons why this could be so, but it is important to consider whether for a specific purpose such as the establishment of economically or operationally sensitive regulations for fisheries or other activities, the level of accuracy in our models is sufficient, particularly in the face of environmental variability and uncertainty. We would argue that despite the uncertainties, such models can already be of great applied value. For example, if we were to use the observed distributions of black-browed albatrosses from New Island to inform the management of the Southern Patagonian shelf, the modeling results presented here illustrate that the 2008/2009 data were likely to be typical of the average conditions in the last decade, leading to the conclusion that the importance of the Staten Island area was over-estimated by the 2009/2010 observations, and hence it should not rank as high as other priority sectors in the W-SW of West Falkland.

\subsection{Conclusions}

The present study suggests that conclusions regarding the marine distribution of central place foragers, such as albatrosses, may be problematic if spatial and temporal variation in their behavior are not taken into account. Results from one colony cannot be directly extrapolated to a neighboring one, and there may be important inter-annual variation. Models of the foraging distribution of albatrosses have a greater predictive power if accessibility and inter-colony competition are taken into account. Our results also show that at least in some situations, fisheries have a relatively weak influence on foraging decisions of albatrosses at large spatial scales, even in species known to scavenge extensively behind fishing vessels. Current predictive models for predators can provide important insights for the identification of resource hotspots and guide decision-makers, despite the incomplete nature of the information available.

\section{Acknowledgements}

We are grateful to the many fieldworkers who assisted with the study. The New Island Conservation Trust supported field studies on their New Island reserve. Wildlife Conservation Society granted permission for work on Steeple Jason. This study was financed by Fundação para a Ciência e Tecnologia (FCT-Portugal) through Project PTDC/MAR/099366/2008, Project PEst-OE/MAR/UI0331/2011 and through a Grant (SFRH/BD/47378/2008) to R.M. Formal permits and further financial support were received from the Falkland Islands Government. Ian, Georgina and Maria Strange provided important support in the field and in Stanley. We also thank John Barton, Director of Natural Resources for supporting this work.

\section{Appendix A. Supplementary material}

Supplementary data associated with this article can be found, in the online version, at http://dx.doi.org/10.1016/j.pocean.2013. 01.005 . 


\section{References}

Aarts, G., MacKenzie, M., McConnell, B., Fedak, M., Matthiopoulos, J., 2008. Estimating space-use and habitat preference from wildlife telemetry data. Ecography 31, 140-160.

ACAP, 2009. ACAP Species Assessment: Black-browed Albatross Thalassarche melanophris. <http://www.acap.aq> (accessed 01.09.09).

Acha, E.M., Mianzan, H.W., Guerrero, R.A., Favero, M., Bava, J., 2004. Marine fronts at the continental shelves of austral South America Physical and ecological processes. Journal of Marine Systems 44, 83-105.

Agnew, D.J., 2002. Critical aspects of the Falkland Islands pelagic ecosystem: distribution, spawning and migration of pelagic animals in relation to oil exploration. Aquatic Conservation: Marine and Freshwater Ecosystems 12, 3950.

Ainley, D.G., Ribic, C.A., Ballard, G., Heath, S., Gaffney, I., Karl, B.J., Barton, K.J., Wilson, P.R., Webb, S., 2004. Geographic structure of Adelie Penguin populations: overlap in colony-specific foraging areas. Ecological Monographs 74, 159-178.

Arkhipkin, A.I., Brickle, P., Laptikhovsky, V.V., 2010. Usage of the island water dynamics by spawning red cod, Salilota australis (Pisces: Moridae) on the Falkland Islands shelf (Southwest Atlantic). Fisheries Research 105, 156-162.

Arkhipkin, A.I., Brickle, P., Laptikhovsky, V., Winter, A., 2012. Dining hall at sea: feeding migrations of nektonic predators to the eastern Patagonian Shelf. Journal of Fish Biology 81, 882-992.

Bartumeus, F., Giuggioli, L., Louzao, M., Bretagnolle, V., Oro, D., Levin, S.A., 2010. Fishery discards impact on seabird movement patterns at regional scales. Current Biology 20, 215-222. http://dx.doi.org/10.1016/j.cub.2009.11.073.

Bentamy, A., Grodsky, S.A., Carton, J.A., Croizé-Fillon, D., Chapron, B., 2012. Matching ASCAT and QuikSCAT winds. Journal of Geophysical Research 117, C02011. http://dx.doi.org/10.1029/2011JC007479.

Block, B.A., Jonsen, I.D., Jorgensen, S.J., Winship, A.J., Shaffer, S.A., Bograd, S.J., Hazen, E.L., Foley, D.G., Breed, G.A., Harrison, A.L., Ganong, J.E., Swithenbank, A., Castleton, M., Dewar, H., Mate, B.R., Shillinger, G.L., Schaefer, K.M., Benson, S.R., Weise, M.J., Henry, R.W., Costa, D.P., 2011. Tracking apex marine predator movements in a dynamic ocean. Nature 475, 86-90.

Boltovskoy, D. (Ed.), 1999. South Atlantic Zooplankton. Backhuys Publishers, Leiden.

Boyd, I., Wanless, S., Camphuysen, C.J. (Eds.), 2006. Top Predators in Marine Ecosystems. Their Role in Monitoring and Management. Conservation Biology Series, vol. 12. Cambridge University Press, Cambridge.

Burnham, K.P., Anderson, D.R., 2002. Model Selection and Multimodel Inference: A Practical Information-theoretic Approach, second ed. Springer-Verlag, Berlin.

Cairns, D.K., 1989. The regulation of seabird colony size - a hinterland model. American Naturalist 134, 141-146.

Catry, P., Phillips, R.A., Forcada, J., Croxall, J.P., 2006. Factors affecting the solution of a parental dilemma in albatrosses: at what age should chicks be left unattended? Animal Behaviour 72, 383-391. http://dx.doi.org/10.1016/ j.anbehav.2005.10.030.

Christiansen, C.L., Morris, C.N., 1997. Hierarchical Poisson regression modelling. Journal of the American Statistical Association 92, 618-632.

Falabella, V., Campagna, C., Croxall, J. (Eds.), 2009. Atlas del Mar Patagónico. Especies y espacios. Wildlife Conservation Society y BirdLife International, Buenos Aires.

Furness, R.W., Birkhead, T.R., 1984. Seabird colony distributions suggest competition for food supplies during the breeding season. Nature 311, 655-656.

Granadeiro, J.P., Phillips, R.A., Brickle, P., Catry, P., 2011. Albatrosses following fishing vessels. How badly hooked are they on an easy meal? PLoS One 6, e17467.

Grémillet, D., Dell’Omo, G., Ryan, P.G., Peters, G., Ropert-Coudert, Y., Weeks, S.J., 2004. Offshore diplomacy, or how seabirds mitigate intra-specific competition: a case study based on GPS tracking of Cape gannets from neighboring colonies. Marine Ecology Progress Series 268, 265-279.

Grünbaum, D., Veit, R.R., 2003. Black-browed albatrosses foraging on Antarctic krill: density-dependence through local enhancement? Ecology 84, 3265-3275.

Huin, N., 2002. Foraging distribution of the black-browed albatross, Thalassarche melanophris, breeding in the Falkland Islands. Aquatic Conservation - Marine and Freshwater Ecosystems 12, 89-99.

Huin, N., Reid, T., 2007. Census of the Black-browed Albatross Population of the Falkland Islands. Falkland Conservation, Stanley.

Hyrenbach, K.D., Dotson, R.C., 2003. Assessing the susceptibility of female blackfooted albatross (Phoebastria nigripes) to longline fisheries during their postbreeding dispersal: an integrated approach. Biological Conservation 112, 391404

Hyrenbach, K.D., Forney, K.A., Dayton, P.K., 2000. Marine protected areas and ocean basin management. Aquatic Conservation - Marine and Freshwater Ecosystems 10, 437-458.

IUCN, 2008. IUCN Red List of Threatened Species. <www.iucnredlist.org> (accessed 01.09.09).

Kappes, M.A., Shaffer, S.A., Tremblay, Y., Foley, D.G., Palacios, D.M., Robinson, P.W., Bograd, S.J., Costa, D.P., 2010. Hawaiian albatrosses track interannual variability of marine habitats in the North Pacific. Progress in Oceanography 86, 246-260.

Lewis, S., Sherratt, T.N., Hamer, K.C., Wanless, S., 2001. Evidence of intra-specific competition for food in a pelagic seabird. Nature 412, 816-819.

Louzao, M., Pinaud, D., Péron, C., Delord, K., Wiegand, T., Weimerskirch, H., 2011. Conserving pelagic habitats: seascape modelling of an oceanic top predator.
Journal of Applied Ecology 48, 121-132. http://dx.doi.org/10.1111/j.13652664.2010.01910.x

Masello, J.F., Mundry, R., Poisbleau, M., Demongin, L., Voigt, C.C., Wikelski, M., Quillfeldt, P., 2010. Diving seabirds share foraging space and time within and among species. Ecosphere 1. http://dx.doi.org/10.1890/ES10-00103.1, article 19.

Matthiopoulos, J., 2003. The use of space by animals as a function of accessibility and preference. Ecological Modeling 159, 239-268.

Peterson, S.L., Phillips, R.A., Ryan, P.G., Underhill, L.G., 2008. Albatross overlap with fisheries in the Benguela Upwelling System: implications for conservation and management. Endangered Species Research 5, 117-127.

Phillips, R.A., Silk, J.R.D., Croxall, J.P., Afanasyev, V., 2006. Year-round distribution of white-chinned petrels from South Georgia: relationships with oceanography and fisheries. Biological Conservation 129, 336-347.

Pierre, J.P., Abraham, E.R., Middleton, D.A.J., Cleal, J., Bird, R., Walker, N.A., Waugh, S.M., 2010. Reducing interactions between seabirds and trawl fisheries: responses to foraging patches provided by fish waste batches. Biological Conservation 143, 2779-2788.

R Development Core Team, 2009. R: A Language and Environment for Statistical Computing. Vienna, Austria, <http://www.R-project.org>.

Risien, C.M., Chelton, D.B., 2008. A global climatology of surface wind and wind stress fields from eight years of QuikSCAT Scatterometer data. Journal of Physical Oceanography 38, 2379-2413.

Schiavini, A., Frere, E., Yorio, P., Parera, A., 1999. Las aves marinas de la Isla de los Estados, Tierra del Fuego, Argentina: revision histórica, estado poblacional y problemas de conservacion. Anales Instituto Patagonia, Serie Cs. Nat. (Chile) 27 $25-40$.

Schlitzer, R., 2010. Ocean Data View. <http://odv.awi.de>

Skov, J., Durinck, J., 2001. Seabird attraction to fishing vessels is a local process. Marine Ecology Progress Series 214, 289-298.

Strange, I.J., 2008. Aerial surveys of black-browed albatross Thalassarche melanophris breeding colonies in the Falkland Islands: the methodology employed and comparisons with surveys carried out in 1986, 2005, 2006 and 2007. Design in Nature \& Falkland Islands Wildlife, Stanley.

Sullivan, B.J., Reid, T.A., Bugoni, L., 2006. Seabird mortality on factory trawlers in the Falkland Islands and beyond. Biological Conservation 131, 495-504.

Terauds, A., Gales, R., Baker, G.B., Alderman, R., 2006. Foraging areas of blackbrowed and grey-headed albatrosses breeding on Macquarie Island in relation to marine protected areas. Aquatic Conservation - Marine and Freshwater Ecosystems 16, 133-146.

Trathan, P.N., Green, C., Tanton, J., Peat, H., Poncet, J., Morton, A., 2006. Foraging dynamics of macaroni penguins Eudyptes chrysolophus at South Georgia during brood-guard. Marine Ecology Progress Series 323, 239-251.

Thompson, D., Moss, S.E., Lovell, P., 2003. Foraging behavior of South American fur seals Arctocephalus australis: extracting fine scale foraging behavior from satellite tracks. Marine Ecology Progress Series 260, 285-296.

Tremblay, Y., Bertrand, S., Henry, R.W., Kappes, M.A., Costa, D.P., Shaffer, S.A., 2009 A review of analytical approaches to investigate seabird-environment interactions. Marine Ecology Progress Series 391, 153-163.

Votier, S.C., Bearhop, S., Witt, M.J., Inger, R., Thompson, D., Newton, J., 2010 Individual responses of seabirds to commercial fisheries revealed using GPS tracking, stable isotopes and vessel monitoring systems. Journal of Applied Ecology 47, 487-497.

Wakefield, E.D., Phillips, R.A., Matthiopoulos, J., 2009a. Quantifying the habitat use and preference of pelagic seabirds using individual movement data: a review. Marine Ecology Progress Series 391, 165-182.

Wakefield, E.D., Phillips, R.A., Matthiopoulos, J., Fukuda, A., Higuchi, H., Marshall G.J., Trathan, P., 2009b. Wind field and sex constrain the flight speeds of central place foraging albatrosses. Ecological Monographs 79, 663-679.

Wakefield, E.D., Phillips, R.A., Trathan, P.N., Arata, J., Gales, R., Huin, N., Robertson, G., Waugh, S.M., Weimerskirch, H., Matthiopoulos, J., 2011. Habitat preference, accessibility and competition limit the global distribution of breeding blackbrowed albatrosses. Ecological Monographs 81, 141-167.

Wanless, S., Harris, M.P., 1993. Use of mutually exclusive foraging areas by adjacent colonies of blue-eyed shags (Phalacrocorax atriceps) at South Georgia. Colonial Waterbirds 16, 176-182.

Waugh, S.M., Weimerskirch, H., Cherel, Y., Shankar, U., Prince, P.A., Sagar, P.M., 1999. Exploitation of the marine environment by two sympatric albatrosses in the Pacific Southern Ocean. Marine Ecology Progress Series 177, 243-254.

Weimerskirch, H., Bartle, J.A., Jouventin, P., Stahl, J.C., 1988. Foraging ranges and partitioning of feeding zones in three species of southern albatrosses. Condor 90, 214-219.

Weimerskirch, H., Guionnet, T., Martin, J., Shaffer, S.A., Costa, D.P., 2000. Fast and fuel efficient? Optimal use of wind by flying albatrosses. Proceedings of the Royal Society B 267, 1869-1874.

Weimerskirch, H., LeCorre, M., Kai, E.T., Marsac, F., 2010. Foraging movements of great frigatebirds from Aldabra Island: relationship with environmental variables and interactions with fisheries. Progress in Oceanography 86, 204213.

White, R.W., Gillon, K.W., Black, A.D., Reid, J.B., 2002. The Distribution of Seabirds and Marine Mammals in Falkland Island Waters. Joint Nature Conservation Committee, UK.

Xavier, J.C., Trathan, P.N., Croxall, J.P., Wood, A.G., Podestá, G., Rodhouse, P.G., 2004 Foraging ecology and interactions with fisheries of wandering albatrosses (Diomedea exulans) breeding at South Georgia. Fisheries Oceanography 13, 324344. http://dx.doi.org/10.1111/j.1365-2419.2004.00298.x. 